\title{
4 - Desindustrialização e promessas de modernidade capitalista
}

\author{
Marcio Pochmann
}

SciELO Books / SciELO Livros / SciELO Libros

POCHMANN, M. Desindustrialização e promessas de modernidade capitalista. In: Brasil sem industrialização: a herança renunciada [online]. Ponta Grossa: Editora UEPG, 2016, pp. 148-176.

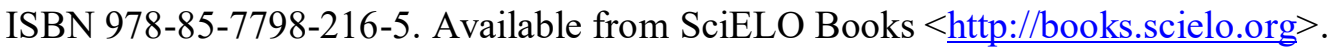

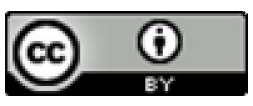

All the contents of this work, except where otherwise noted, is licensed under a Creative Commons Attribution $\underline{4.0 \text { International license. }}$

Todo o conteúdo deste trabalho, exceto quando houver ressalva, é publicado sob a licença Creative Commons Atribição 4.0.

Todo el contenido de esta obra, excepto donde se indique lo contrario, está bajo licencia de la licencia Creative Commons Reconocimento 4.0. 


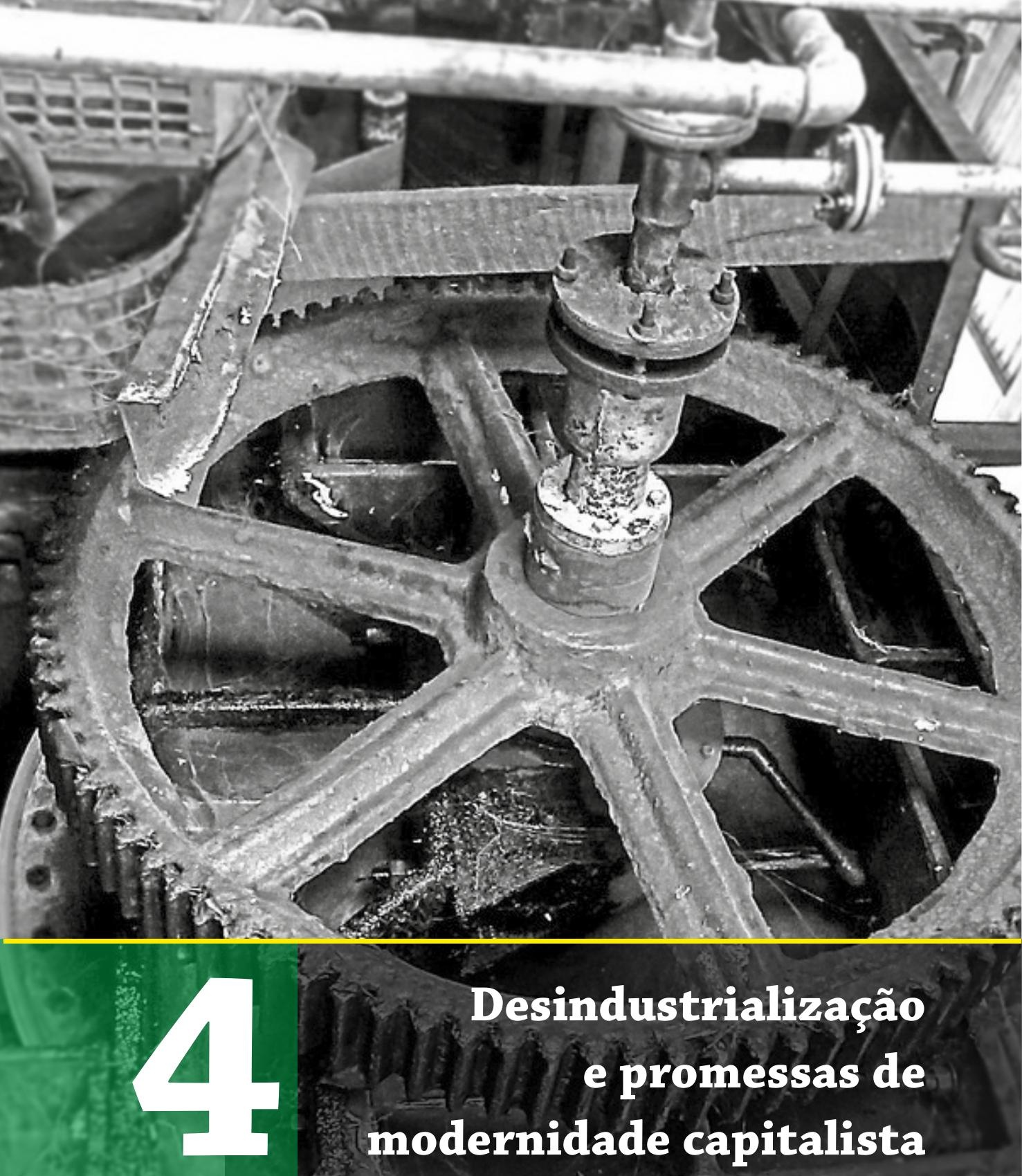


Neste início do século XXI, poucos são os governos que aceitam abertamente o diagnóstico da trajetória da desindustrialização. Tampouco consultorias de atuação nacional e internacional, bem como organismos multilaterais das Nações Unidas incorporam esse tema abertamente em seus frequentes relatórios.

A despeito disso, o movimento de subordinação do capital industrial à dominância financeira tem sido real no capitalismo atual, seja no seu centro dinâmico, seja na sua periferia enquanto sistema mundo. O deslocamento geográfico da produção manufatureira segue o seu curso, confirmando dessa maneira uma nova fronteira de expansão capitalista na Ásia.

Pela perspectiva neoliberal exposta sempre por governos de plantão em boa parte dos países, a convivência com o enxugamento da participação relativa da indústria no produto somente pode ser revertida com aposta central no determinismo tecnológico. Ou seja, a oportunidade de constituição de uma nova fase dinâmica do progresso técnico capaz de proporcionar a recuperação industrial, para além da ascensão asiática.

A aceitação do poder central das corporações transnacionais a moldar a indústria global na forma das cadeias de organização e distribuição do valor da manufatura, que deixariam de ser apenas produção e venda, incorpora-se como natural no ambiente hegemônico neoliberal. Adicionar-se-iam, assim, as métricas de capturas e formas 
de criação de valor a partir de interconexões-chave na economia mundial.

Essas mudanças, todavia, estariam sendo capturadas parcial e insuficientemente por sistemas ultrapassados de estatísticas e pesquisas sobre a produção e valor da manufatura. Como no velho sistema de manufatura, o modelo atual de classificação industrial não incorpora serviços pré e pós das empresas vinculadas à cadeia de valor e que são crescentemente importantes nos modelos de negócios competitivos das firmas.

O papel dos governos voltar-se-ia a identificar e apoiar focadamente no interior das cadeias de valor, as partes industriais estabelecidas no plano local através da adoção de novas políticas públicas. O que exigiria reconhecer previamente que a produção de manufatura constitui parte de um sistema mais amplo que o anterior, cuja abordagem integrada dos governos articularia na métrica dos sistemas, a ciência, a tecnologia, a inovação e as políticas industriais.

Para tanto, a postura passiva dos governos à determinação do comércio e investimento global sobre a estrutura e desempenho da produção industrial. Isso porque prevaleceria a fragmentação da produção e distribuição no interior das cadeias de valor que são controladas monopolisticamente pelas corporações transnacionais.

Como incluem tanto terceirização de funções como o offshoring de componentes, os custos e qualidade de trabalho, transporte, tributação, câmbio, juros, entre outros, favorecem ainda mais o acirramento da competição entre países. No mesmo sentido, o acirramento da competição por recursos naturais, tornando seus preços mais altos e voláteis, faria mais vulnerável o conjunto das cadeias de abastecimento globais sob o efeito das mudanças climáticas. 
Tudo isso resultaria na nova indústria global, mais próxima de uma espécie de economia circular, cujos produtos finais seriam reutilizados, reciclados e remanufaturados. Assim, a mudança no valor dos componentes da indústria frente à escassez de recursos e custos mais elevados de energia e eliminação de resíduos.

Como se percebe, o determinismo da tecnologia encontra função central para gerar a mudança. Em grande medida, o valor que estaria sendo criado nos próximos anos resultaria das inovações inesperadas, assim como daquelas que estão emergindo pela manufatura aditiva e integrada em produtos e redes das tecnologias de informação e comunicação, sensores, materiais avançados e robótica.

Os novos sistemas de digitalização (computação pervasive, tecnologias de software e sensores avançados) contribuem para cadeias de valor com gestão das relações com clientes, controle de processos, verificação do produto, logística, rastreabilidade dos produtos e sistemas de segurança. Da mesma forma, a fabricação do futuro incluiria locais de produção como a própria casa no campo ou na cidade, com a mudança de paradigma na relação entre o trabalho e a vida humana.

A nova era de fabricação está sendo marcada por empresas em rede que utilizam informações e análises tão habilmente como empregam talentos e máquinas para oferecer produtos e serviços a diversos mercados globais (MCKINSEY; COMPANY, 2012; DELOITTE, 2013). A condição de adaptabilidade tende a permear quase todos os aspectos da produção, da pesquisa e desenvolvimento à inovação, dos processos de produção, fornecedores e interdependências aos clientes e a manutenção de produtos e reparação.

Noutra perspectiva de natureza não liberal, o padrão de industrialização fordista liderado pelos Estados Unidos desde o final da segunda Guerra Mundial teria expressado os sinais de esgotamento 
ainda na década de 1970, quando emergiram diversos movimentos críticos à ilusão do fim da História pelas sociedades urbanas e industriais. Com a irrupção das manifestações estudantis de Paris em 1968 e generalizadas para várias cidades do mundo, uma nova fase de contestações sociais, econômicas, culturais e políticas foi inaugurada no ambiente capitalista de dimensão global.

A magnitude da recusa crítica à trajetória do capitalismo industrial, especialmente nas economias desenvolvidas, sustentou a difusão teórica e prática das principais vertentes de naturezas evolutiva e transformista no interior das sociedades urbanas e industriais fundada, ambas, no determinismo tecnológico. De um lado, a vertente evolutiva do capitalismo teve grande envergadura com estudos e proposições associadas à concepção de transição para uma nova sociedade pós-industrial.

Assim como a emergência da primeira Revolução Industrial havia desencadeado desde a metade do século XVIII a passagem da antiga sociedade agrária para a urbana e industrial, o capitalismo estaria acumulando avanços inéditos nos serviços protagonizados pelo curso da terceira Revolução Industrial. Não obstante o reposicionamento no interior das estruturas produtivas das sociedades, com o agigantamento do setor de serviços e o esvaziamento relativo da indústria, o ritmo de expansão econômica decaiu sensivelmente. Na sequência, a desindustrialização passou a ser notada e cada vez mais associada à tendência de uma estagnação secular, com desemprego estrutural e elevada polarização das estruturas sociais entre ricos e pobres e, ainda, o aniquilamento da classe média assalariada.

De outro lado, a perspectiva de vertente transformista no capitalismo que reconheceu a insustentabilidade ambiental frente à continuidade do progresso econômico sem travas pela sociedade urbana e 
industrial. A crença de que a mudança tecnológica seria suficiente para gestar outra estrutura industrial de baixo carbono ganhou apoio das grandes corporações transnacionais para montar as cadeias globais de valor, uma vez que elas monopolizam parcela consideráveis dos recursos aplicados no mundo aos investimentos em progresso técnico.

Para tratar da problemática da desindustrialização e suas perspectivas de enfrentamento, este capítulo procurou abordar criticamente as contradições presentes nas duas principais vertentes orientadoras do debate atual sobre o futuro da produção e distribuição da manufatura no mundo. A sua melhor compreensão visa contribuir para o necessário reposicionamento brasileiro frente à tendência da semiestagnação da renda per capita concomitante com o apequenamento da industrialização.

\section{O mito da sociedade pós-industrial na estagnação secular}

Após registrar uma das trajetórias mais exitosas em termos de expansão de suas forças produtivas convergentes com o processo de medianização da estrutura social por quase trinta anos ao final da segunda Guerra Mundial, o centro do capitalismo mundial passou a se encontrar novamente diante de mais uma grande crise. Sem solução a vista, a turbulência de dimensão global iniciada em 2008 passou a equivaler-se cada vez mais às grandes depressões que varreram o mundo como em 1873 - 1896 e em 1929 - 1939.

Em todas as grandes crises, o deslocamento geográfico do núcleo dinâmico mundial apresentou-se como um problema complexo frente à assimetria que decorre da relação do centro com a periferia, imposta 
pelo capitalismo de desenvolvimento desigual e combinado. Enquanto no último quartel do século XIX, a longa decadência do domínio inglês teve início com a emergência da segunda Revolução Industrial e o fim do capitalismo de livre competição, a grande Depressão de 1929 consolidou a hegemonia estadunidense sobre a Alemanha, derrotada nas duas grandes Guerras Mundiais (1914-18 e 1939-45).

Neste começo do século XXI, a polarização ascendente entre Estados Unidos e China concede foco ao tema controverso da transição atual no interior do centro dinâmico capitalista mundial. De um lado, a nova fronteira de expansão capitalista aberta a partir da Ásia, cujo vetor principal tem sido o rápido e considerável processo de monopolização do capital expresso por meio do avanço nas cadeias globais de valor (GLATTFELDER, 2013; MILBERG; WINKLER, 2013; ROTHHOPF, 2008).

O grau de concentração e centralização do capital em algumas poucas corporações transnacionais transcorre simultaneamente ao sistema fragmentado da produção que recorta os territórios nacionais, cada vez mais interligados pelos avanços da terceira Revolução Industrial. Atualmente, não mais do que trezentas regiões territoriais dispersas no mundo encontram-se conectadas e articuladas ao modo capitalista global de produção e distribuição, comprometendo o funcionamento das políticas públicas e esvaziando o grau de autonomia dos Estados Nacionais (NARODOWSKI; LENICOV, 2012; DREIFUSS, 2004).

De outro lado, a decadência do padrão de industrialização e regulação fordista desde a década de 1970 segue acompanhada por consequente desestruturação da sociedade salarial, especialmente aquela conformada pela maior proximidade entre a base e o cume da estrutura social. Assiste-se, assim, à transição das tradicionais classes médias assalariadas e de trabalhadores industriais para o novo e 
extensivo precariado (STANDING, 2013; BECK, 1999; BRAGA, 2012; POCHMANN, 2012).

A perspectiva engajada dos ideólogos do capitalismo tem sido, todavia, muito distinta. Diante dos sinais de bloqueio ao ciclo de expansão das forças produtivas com avanços na sociedade de consumo de massa ainda nos anos de 1970, as respostas apresentadas direcionavam-se ao entendimento de uma significativa oportunidade de transição evolutiva ao padrão civilizatório superior.

Em síntese, a visão convergente de que a terapia das políticas neoliberais teria por função libertar o espírito empreendedor das novas forças produtivas capitalistas concomitantemente com a emergência da terceira Revolução Industrial e Tecnológica (DAVIS et al, 2006; ELLSBERG, 2011; ANDERSON, 2013).

Embalados por certo determinismo tecnológico e saltos imaginados na produtividade do trabalho imaterial, uma nova gama de promessas foi sendo forjada pela direção à almejada sociedade do tempo livre estendida pelo avanço do ócio criativo, da educação em integral e da contenção do trabalho heterônomo (apenas pela sobrevivência). Penetrados cada vez mais pela cultura midiática do individualismo e pela ideologia da competição, o neoliberalismo seguiu ampliando apoiadores no mundo.

A propaganda de elevação da expectativa de vida para próximo de 100 anos de idade abriria inédita perspectiva à postergação do ingresso no mercado de trabalho para a juventude completar o ensino superior, estudar a vida toda e trabalhar com jornadas semanais de até 12 horas. A nova sociedade pós-industrial estaria a oferecer um padrão civilizatório jamais alcançado pelo modo capitalista de produção e distribuição (MASI, 1999; REICH, 2002; SANTOS; GAMA, 2008). 
Sob este manto de promessas de maior libertação do trabalho humano na luta pela sobrevivência (trabalho heterônomo) através da postergação da idade de ingresso no mercado de trabalho para somente depois do cumprimento do ensino superior, bem como da oferta educacional ao longo da vida, que o racionalismo neoliberal se constituiu. De certa forma, o entendimento de que o esvaziamento do peso relativo da economia nacional proveniente dos setores primário (agropecuária) e secundário (indústria e construção civil) consagraria expansão econômica superior ao setor terciário (serviços e comércio).

Resumidamente, uma sociedade pós-industrial protagonizadora de conquistas superiores aos marcos do acordo socialdemocrata do segundo após guerra (ARON, 1981; BELL, 1973).

Aliado a isso, a sustentação do meio ambiente ganhou maior importância com a necessidade de mudanças no modelo de produção e consumo de alto carbono e que permitiria levar à economia tecnologicamente avançada e assentada no processo de transição à desmaterialização da produção. Tudo isso pressuporia dar conta do estado de saúde do conjunto da população, da dimensão do conhecimento e da perspectiva do trabalho humano (ALTVATER, 1995; ALIER, 2005; O’CONNOR, 1994).

No que concerne ao estado da educação destaca-se o reconhecimento a priori acerca da atual modificação demográfica, com redução, em geral, da parcela mais jovem e elevação do segmento etário mais velho. Ao mesmo tempo, percebe-se o aumento na expectativa média de vida, o que recoloca um conjunto de novas questões para as políticas de saúde, mobilidade, integração social, entre outras.

Cada vez mais se apresenta como possibilidade a expectativa de vida em torno dos 100 anos de idade, frente aos atuais 65 anos. Ademais da importante queda na taxa de mortalidade infantil, assiste-se 
à aceleração da redução na taxa de fecundidade feminina e do número de membros por domicílios. Frente a isso, ganham maior importância as novas estruturas familiares, muitas delas cada vez mais monoparentais, com crescente dificuldade de reprodução tradicional da sociabilidade domiciliar.

Acresce também ressaltar o estado de saúde da população, aquela expressa pela nova composição das causas de mortes. As doenças transmissíveis e por causas associadas a condições nutricionais, maternas e perinatais perdem importância relativa frente ao aumento das causas associadas às doenças não transmissíveis (cardiovasculares, psiquiátricas e neoplasias) e às causas externas (acidente de trânsito e violência).

Embora os recursos públicos e privados continuem a crescer nos orçamentos com saúde, o quadro de insegurança permanece preocupante. Em geral, o crime de violência atinge muito mais os jovens, especialmente os de sexo masculino e pertencentes às famílias de baixa renda.

No mesmo sentido, a carência de infraestrutura decente no meio urbano associa-se às precárias condições de mobilidade urbana, dos meios de transportes coletivos e individuais, não sendo desprezíveis as mortes ocasionadas por acidentes de trânsito. Assim, o estado de saúde da população requer, cada vez mais, políticas intersetoriais e articuladas que assistam a população em sua totalidade.

Para a dimensão do conhecimento, não obstante avanço colhido no processo educacional, sabe-se que há inegáveis descompassos e assimetrias ainda consideráveis em todo o território mundial. A começar pelo grau de analfabetismo populacional ainda persistente neste início do século XXI. 
Isso cresce de proporção se forem contabilizados os chamados analfabetos funcionais. Em geral, a concentração dos pobres e miseráveis e a maior taxa de desemprego e ocupações precárias assentam-se na população de menor escolaridade.

Nesse sentido que o sistema educacional tal como existe atualmente se apresenta relativamente recente e com sinais inegáveis de insuficiência. Até a transição da antiga sociedade agrária para a urbana e industrial, a educação era algo inexistente para as grandes massas da população. Tão somente as famílias aristocratas possuíam condições de contratar tutores para filhos, enquanto a Igreja era a instituição que tratava de transferir o conhecimento formalizado ao longo dos anos.

No mundo agrário, o conhecimento comunitário era transmitido na velha forma "de pai para filho", em que os mais idosos possuíam importância relativa superior devido ao acúmulo das experiências vividas. De maneira geral, somente a passagem para a sociedade urbana e industrial alterou o papel da educação a partir da construção e difusão das escolas formais.

Antes disso, a questão nacional foi constituída pelo aparecimento dos Estados nacionais a partir do século XIX, tornando-se fundamental para a generalização da condição de povo associado aos limites da soberania de uma nação. Assim, a unificação da língua pátria e a identificação dos valores nacionais se mostraram fundamentais para a formação do conteúdo da educação formal.

Ademais, a emergência do trabalho na manufatura passou a exigir valores como disciplina e responsabilidade fabril, bem como operações básicas e linguagem comum, não mais transmitidas pelas famílias que viviam em comunidades na sociedade agrária. Nas cidades, o conjunto das famílias não somente diminuiu de tamanho 
como o trabalho passou a ser realizado pelos pais e distante do local de moradia.

A crise de sociabilidade no interior das famílias pertencentes à sociedade urbana e industrial terminou sendo enfrentada pela ação das políticas públicas. Com a difusão dos sistemas educacionais pelo Estado, o segmento etário de até 14 anos foi libertado do trabalho, conforme ocorria na sociedade agrária, passando a inatividade necessária para cumprir o conteúdo do ensino como elemento fundante para o ingresso no mercado de trabalho.

Uma vez coberta a fase infantil de estudo, a passagem para o mercado de trabalho afastava dos bancos escolares. Assim, a educação do século XX se apresentou funcional aos requisitos de conformação dos Estados nacionais e de transição da inatividade ao mundo do trabalho.

Com a terceira Revolução Industrial, que tem a emergência das novas tecnologias de comunicação e informação, as exigências educacionais ampliaram-se rapidamente. Não parecem caber mais sistemas educacionais voltados apenas às fases etárias precoces.

Ademais de tornar o ensino superior o piso da nova sociedade do conhecimento, urge a instalação do sistema de educação para toda a vida. Se o conhecimento assume cada vez mais a condição de principal ativo gerador de riqueza, qual o sentido de se estudar pouco e em condições desfavoráveis?

Em pleno curso da transição para a sociedade de serviços, a inserção no mercado de trabalho precisa ser gradualmente postergada, possivelmente para o ingresso na atividade laboral somente após a conclusão do ensino superior, com idade acima dos 22 anos, e a saída sincronizada do mercado de trabalho para o avanço da inatividade. Tudo isso acompanhado por jornada de trabalho reduzida, o que 
permitiria observar que o trabalho heterônomo deveria corresponder a não mais do que $25 \%$ do tempo da vida humana.

Neste sentido que foi apresentada a nova perspectiva do trabalho humano. $\mathrm{Na}$ antiga sociedade agrária, destaca-se que o começo do trabalho ocorria a partir dos 5 a 6 anos de idade para se prolongar até praticamente a morte, com jornadas de trabalho extremamente longas (14 a 16 horas por dia) e sem períodos de descanso, como férias e inatividade remunerada (aposentadorias e pensões). Para alguém que conseguisse chegar aos 40 anos de idade, tendo iniciado o trabalho aos 6 anos, por exemplo, o tempo comprometido somente com as atividades laborais absorvia cerca de $70 \%$ de toda a sua vida.

$\mathrm{Na}$ sociedade industrial, o ingresso no mercado laboral foi postergado para os 16 anos de idade, garantindo aos ocupados, a partir daí, o acesso a descanso semanal, férias, pensões e aposentadorias provenientes da regulação pública do trabalho. Com isso, alguém que chegasse ao mercado de trabalho depois dos 15 anos de idade e permanecesse ativo por mais 50 anos, teria, possivelmente, mais alguns anos de inatividade remunerada (aposentadoria e pensão).

Assim, cerca de 50\% do tempo de toda a vida estariam comprometidos com o exercício do trabalho heterônomo. A parte restante do ciclo da vida não comprometida pelo trabalho e pela sobrevivência deveria estar associada à reconstrução da sociabilidade, estudo e formação, cada vez mais exigidos pela nova organização da produção e distribuição internacionalizada.

Isso porque, diante dos elevados e constantes ganhos de produtividade, tornar-se-ia possível reduzir o tempo semanal de trabalho de algo em torno de 40 horas para não mais que 20 horas. De certa forma, a transição entre as sociedades urbano-industrial e pós-industrial tende a não mais separar nítida e rigidamente o tempo de trabalho do não 
trabalho, podendo gerar maior mescla entre os dois, com maior intensidade e risco da longevidade ampliada da jornada laboral para além do tradicional local de exercício efetivo do trabalho.

Dentro deste contexto que se recoloca em novas bases a relação do tempo de trabalho heterônomo e a vida. Em geral, o funcionamento do mercado de trabalho relaciona ao longo do tempo uma variedade de formas típicas e atípicas de uso e remuneração da mão de obra com excedente de força de trabalho derivado dos movimentos migratórios internos e externos sem controles.

Em vários países, a ausência das reformas clássicas do capitalismo contemporâneo, como a agrária, possibilitou a transferência de grande parcela do excedente rural dos trabalhadores para as cidades. Também sem planejamento, as cidades absorveram grandes contingentes de trabalhadores alocados em formas marginais de ocupação, cuja informalidade inviabilizou o trabalho decente. Os escassos experimentos de democracia nas relações de trabalho comprometeram o potencial de atuação dos sindicatos nas formas de contratações coletivas mais próximas dos ganhos de produtividade alcançados nos setores econômicos.

Após quase quatro décadas da geração de promessas voltadas à construção de uma sociedade pós-industrial superior, assiste-se ao aprofundamento dos sinais inegáveis de regressão no interior da sociedade do capital. Do progresso registrado em torno da construção de uma estrutura social medianizada por políticas de caráter socialdemocrata a partir da segunda metade do século passado, constata-se, neste início do século XXI, o retorno à forte polarização social (BOLTANSKI; CHIAPELLO, 2009; LOJIKINE, 2005; KUMAR, 1997).

Por uma parte, a degradação da estrutura social herdada da industrialização fordista tem desconstituído ampla parcela da classe média, fortalecendo expansão do novo precariado. Por outra, a concentração 
de ganhos significativos de riqueza e renda em segmento minoritária da população gera um contexto social inimaginável, em que somente $1 \%$ da população mundial chega a deter mais riqueza concentrada que a somatória do conjunto dos $99 \%$ dos habitantes da Terra.

Gráfico 01 - Estados Unidos: evolução da taxa de produtividade média anual por decênio (em \%)

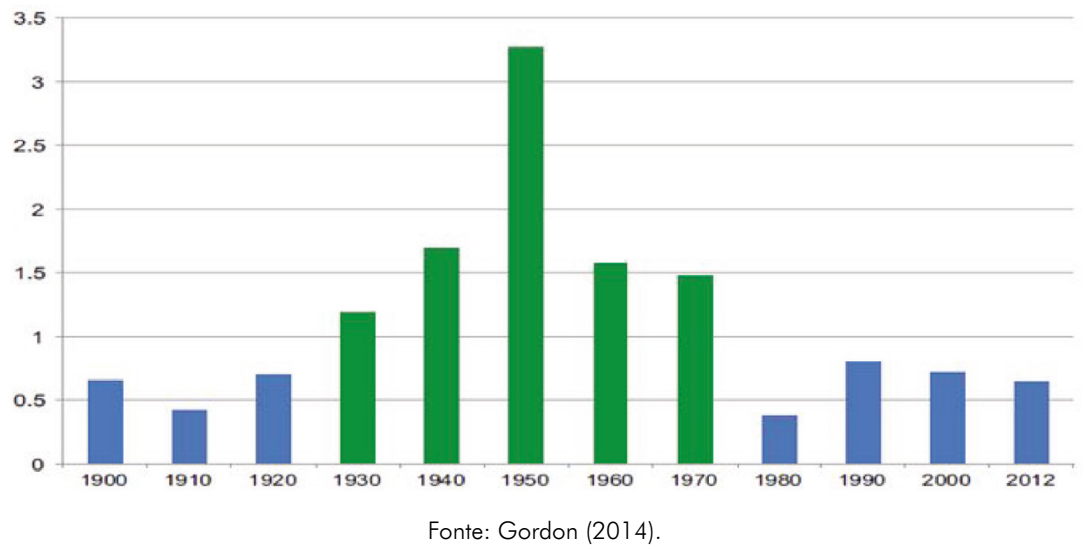

Em mais de três décadas de predomínio da regulação neoliberal do capitalismo, as promessas da construção de padrão civilizatório superior encontram-se desfeitas. Os avanços ocorridos têm sido para poucos, enquanto o retrocesso observado serve a muitos.

Ao contrário, o que vem se consolidando no horizonte, sobretudo dos países capitalistas avançados tem sido a tendência à estagnação secular. Com oito anos de manifestação da crise de dimensão global iniciada em 2008, a recuperação ainda encontra-se anêmica e distante, não obstante taxas de juro reais negativas e medidas outras de elevação do nível de atividade econômica terem sido adotadas sem sucesso. 
O comportamento da produtividade que já apresentava em desaceleração no ambiente pré-crise de 2008 decaiu mais e encontra-se próximo de zero. Neste sentido que a hipótese de estagnação tem se tornado relevante, pois a crise de dimensão global tem comprometido a capacidade de expansão das economias capitalistas.

As garantias do pensamento liberal conservador sobre investimento em educação e inovação tecnológica, bem como a liberalização dos mercados e o encolhimento dos governos não têm evitado a desaceleração da produtividade e, por consequência, o baixo dinamismo econômico para conjunto dos países. Por conta disso, a hipótese da estagnação secular lançada por Alvin Hansen, em 1939, para tratar das possibilidades de recuperação econômica estadunidense durante os efeitos da Grande Depressão de 1929 foi novamente recuperada e concedida atualidade a partir da crise de dimensão global iniciada em 2008.

Pela análise de Hansen, o capitalismo tenderia a estagnação diante da fragilidade das iniciativas dos governos da época em recuperar a economia, cuja marca seria o registro do elevado desemprego e piora acentuada na renda da população. Mesmo as inovações tecnológicas introduzidas desde a década de 1920 se mostravam insuficientes para instaurar e manter o dinamismo econômico, amplamente dependente das forças de mercado (HANSEN, 1939).

O ambiente generalizado de desregulação potencializou as forças de mercado a responsabilidade de condução do dinamismo da produção e circulação de mercadorias, o que foi acompanhado por insuficiência crônica da demanda efetiva. Conforme registra a trajetória da concentração do poder econômico por grandes oligopólios no capitalismo, a capacidade ociosa no interior do sistema de produção torna-se uma constante, esvaziando os investimentos e rebaixando a produtividade (STEIDEL, 1983; MARX, 1983). 
Com a diminuição dos investimentos há, em geral, a possibilidade de elevar-se ainda mais a concentração do poder econômico, com a permanência dos fundamentalmente mais competitivos. E para buscar compensar a queda na taxa de lucro, as empresas restantes contraem a taxa de salários, aprofundando a desigualdade de renda e buscando alternativas de ganhos em outras esferas.

Assim, a dominância financeira se estabeleceu consideravelmente por oferecer possibilidades de rentabilidade superior, ainda que não menos especulativas e arriscadas. Mesmo com capacidade ociosa e insuficiência na demanda efetiva, o setor produtivo busca compensar a queda na taxa de lucro com ganhos financeiros.

$\mathrm{Na}$ sequência, o aparecimento de bolhas financeiras tende a indicar como o transbordamento dos recursos para além da reciclagem e o financiamento de dívidas revelam a fragilidade do capitalismo financeiro. Mas, neste sentido, cresceu a relação dos ativos financeiros globais com o Produto Interno Bruto do mundo, que passou de 1,2 vezes, em 1980, para quase 4 vezes, em 2012.

Gráfico 02 - Evolução da relação entre ativos financeiros globais e o Produto Interno Bruto do mundo em anos selecionados (em \%)

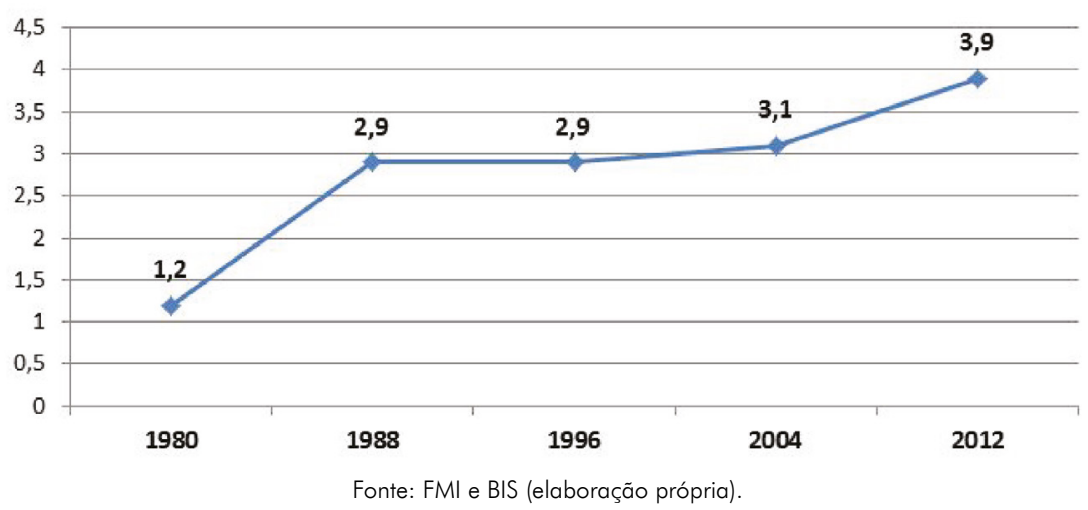


Neste início do século XXI, a evolução das próprias contradições no funcionamento do capitalismo revela a tendência de estagnação no nível geral da produção. Enquanto o Japão expressa mais de duas décadas de paralisia de sua economia, a Europa e os Estados Unidos caminham para a sua primeira década de estagnação desde a crise de 2008.

Gráfico 03 - Estados Unidos: Evolução da taxa real de juros (em \%)

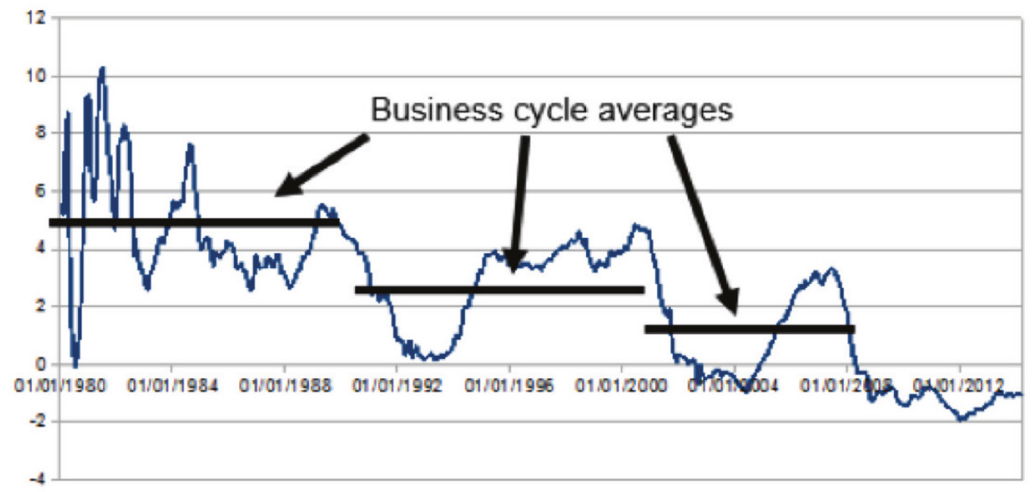

Fonte: Krugman, 2014.

Este novo normal no comportamento estagnante das economias, sobretudo dos países ricos, não encontra nas ações de políticas governamentais anticíclicas, como de taxas de juros reais negativas e expansão da liquidez monetária, a solução. Ademais, ocorrem concomitantemente ao estancamento da produtividade (SUMMERS, 2014; KRUGMAN, 2014; GALBRAITH, 2014; EICHENGREEN, 2015).

A prevalência do baixo dinamismo econômico segue acompanhada pelo elevado desemprego, rebaixamento das rendas do trabalho e maior endividamento do setor público. E combinado com taxas de juros negativas, a impossibilidade de sustentar a estabilidade financeira por longo prazo (KOO, 2009; IMF, 2014; LOHOFF; TRENKLE, 2014). 
Diante do elevado grau de autonomia na condução da política monetária dos Estados Unidos frente à liberalização dos fluxos de capitais, os demais países se mantêm subordinados seus regimes cambiais e taxa de juros. No caso da taxa de juros, sobretudo a de curto prazo, segue afetada pela taxa de juros estadunidense.

Ao se manter inatacável a tendência à estagnação, o futuro do capitalismo sofre maior questionamento, assim como a sua capacidade de atender as promessas às quais circunscreveu o programa de modernidade esperado desde a década de 1970. Neste sentido, a obstrução de um novo padrão civilizatório a ser viabilizado pela transição da sociedade urbano industrial para a pós-industrial.

\section{A ilusão da industrialização de baixo carbono dirigida pelas corporações transnacionais}

A crítica ao padrão civilizatório amparado ao consumismo insustentável ambientalmente surgiu de forma inédita e expressiva concomitante com protestos em várias localidades do mundo ao final da década de 1960. Com a Conferência das Nações Unidas sobre Meio Ambiente, realizada em Estocolmo no ano de 1972, bem como as demais que se seguiram, que protagonizaram o lento e gradual esvaziamento da propulsão revolucionária de modificar sensivelmente o modo de vida urbano e industrial alienado pelo consumismo capitalista.

Isso ocorreu tanto do ponto de vista político, com a "endireitização" ideológica e prática dos partidos que assumiram a causa verde, como econômico frente ao avanço do neoliberalismo e do dirigismo das grandes corporações transnacionais no interior das cadeias globais de produção e distribuição de bens e serviços. Uma farta literatura a 
respeito passou a subsidiar a atuação e proposições diversas do movimento ambientalista supranacional (HARDIN, 1968; MEADOWS et al, 1972; REBÊLO JR, 2002; OLIVEIRA, 2007).

Originalmente, por exemplo, a interpretação crítica ao padrão civilizatório urbano e industrial sobressaiu como uma espécie de neomalthusianismo verde diante do diagnóstico de que a causa da degradação ambiental provinha da expansão demográfica sobre o uso dos recursos naturais. O livro Limites do crescimento que produzido pelo Clube de Roma no início dos anos de 1970 teve grande repercussão frente à defesa radical de, por exemplo, a diminuição em 4/5 do consumo na época de determinadas matérias primas e o limite zero para expansão populacional.

Como o Clube de Roma era financiado por grandes grupos econômicos (Volkswagen, Fiat, Ford, Shell, entre outras) e apresentava relação próxima da OTAN (Organização do Tratado do Atlântico Norte), em plena Guerra Fria, o tema do ambientalismo foi exposto mais aos interesses dos países ricos que se afastavam das perspectivas dos movimentos estudantis, pacifistas e hippies provenientes da década de 1960. Nesse sentido, emergiram as proposições que atendiam aos países que já eram industrializados e haviam completado a transição demográfica, creditando a insustentabilidade ambiental ao descontrole demográfico e à pobreza da população no resto do mundo (RATTNER, 1979; ROGGERO, 1976).

Esta perspectiva ambientalista gerou divisão importante entre os países ricos do Norte que defendiam o crescimento zero e as nações do Sul voltadas à defesa da expansão econômica como superação do atraso social. Mesmo assim, o que mais produziu desconforto foi o questionamento da racionalidade capitalista imposta pela defesa do decrescimento econômico para preservação ambiental.

Por ser estranha a uma economia capitalista, que se constitui enquanto máquina de criação de riqueza, a proposta do crescimento 
zero foi afastada. Ademais, o tema da ausência de expansão econômica seria algo próximo de nações desenvolvidas, sem qualquer referência à geração e repartição da riqueza produzida no mundo, implicando o congelamento do padrão de vida já extremamente desigual (FURTADO, 1974; PERROUX, 1981).

Em função disso que outra proposição ambientalista tomou-se dominante na década de 1980, convergindo interesses econômicos com causas ambientalistas. O conceito inovador do desenvolvimento sustentável adotado se mostrou cada vez mais contraditório com o avanço da hegemonia do neoliberalismo a partir de então.

Conforme o Relatório Brundtland de 1987, o objetivo a ser perseguido seria o desenvolvimento que satisfizesse as necessidades do presente sem comprometer a capacidade das gerações futuras de satisfazerem às suas próprias necessidades. Ao atender o preceito geral sobre o conceito de desenvolvimento sustentável a todos os países, transpareceu a falsa identidade de que em pleno predomínio do neoliberalismo, a riqueza estaria sendo produzida e distribuída menos desigualmente.

Pelo contrário, o que se assistiu por conta do receituário do Consenso de Washington foi a expansão da desigualdade inter e intrapaíses. Talvez por isso que a aposta ao enfrentamento da problemática da degradação ambiental gerada pelo crescimento econômico deslocou-se para soluções de mitigação pelo mercado e de avanço no progresso tecnológico.

Assim, a questão ambiental que apontava originalmente para outro padrão de produção e consumo, assumiu cada vez mais o transformismo de buscar uma industrialização de baixo carbono, dependente de acordos, soluções tecnológicas, informações e investimentos dos capitalistas e governos. No máximo, a busca de uma gestão eficiente dos recursos naturais, o que incorporaria o ambiente enquanto capital ativo no mercado global. 
Mas diante da conformação das cadeias globais de valor, cuja espacialização das atividades econômicas atendeu cada vez mais a custos menores de produção e distribuição, a capacidade dos Estados Nacionais em estabelecer regulações ambientais tendeu a diminuir. A ascensão das grandes corporações transnacionais em meio ao ambiente neoliberal dominante no mundo corresponde quase a monopolização das decisões de como e quanto produzir e a forma de distribuir bens e serviços.

Destaca-se, neste início do século XXI, o modelo de globalização neoliberal, que produziu, entre outras coisas, uma inédita era do poder monopolista privado. Nos dias de hoje, não mais de 500 grandes corporações transnacionais que dominam os setores econômicos estratégicos, respondendo crescentemente pelo comércio mundial dos recursos investidos em pesquisa e desenvolvimento tecnológico.

Por conta disso, nota-se que um contingente reduzido de corporações transnacionais governa qualquer atividade econômica, resultando no aprofundamento do processo de ultramonopolização privada sem paralelo histórico. Essa realidade se torna ainda mais concentrada no poder privado, bem como faz com que não sejam mais os países que tenham empresas, mas grandes corporações empresariais que possuam países, cujo faturamento supera o Produto Interno Bruto de várias nações.

A continuidade da globalização neoliberal tem gerado uma espécie de superentidade global, a controlar decisões econômicas e a interferir dominantemente no poder político do mundo. Isso pode ser observado pela análise de 1.315 corporações transnacionais que conformam a rede capitalista que controla o centro da economia global.

Neste sentido, percebe-se que para este peste pequeno conjunto de corporações transnacionais registra-se um subgrupo que detém o controle de 43,1 mil companhias, o que expressa elevadíssimo grau de monopólio sobre a produção e distribuição de bens e serviços na 
economia global. Resumidamente, somente 1,3 mil corporações transnacionais apropriam-se de $1 / 5$ das receitas globais e controlam quase $2 / 3$ das vendas realizadas no mundo, bem como as ações das principais empresas negociadas nas bolsas de valores.

A força econômica exarada por este centro de comando das corporações transnacional encontra ainda apenas 147 do conjunto das 1,3 mil empresas responsáveis pelo controle de $40 \%$ da riqueza total do mundo. Neste início do século XXI, um pouco mais de $1 \%$ das corporações transnacionais consideradas controlam $2 / 5$ de toda a rede capitalista de produção e distribuição de bens e serviços do mundo.

Resumidamente, encontra-se em funcionamento uma estrutura de comando privado na forma de rede das corporações transnacionais que interfere direta e indiretamente na concorrência e financiamento global. A concentração e centralização da propriedade internacional do capital possui uma arquitetura viabilizada pelo processo de globalização neoliberal que opera a partir de um núcleo de corporações que formam uma espécie de superentidade a controlar decisões econômicas e a interferir dominantemente no poder político do mundo.

A importância relativa das grandes corporações na oferta da produção de bens e serviços de ordem mundial vem sendo cada vez mais significativa. A monopolização da organização capitalista da produção tornou-se uma realidade no plano global.

O poder da formação de preços, que permite a obtenção de lucros extraordinários, bem como o dirigismo tecnológico e o padrão de emprego flexível, gerador de uma classe trabalhadora de precariado (Standing, 2013), ocorrem concomitantemente à monopolização global da produção. O enfraquecimento da regulação pública revela a crescente interação entre a desigualdade e a manipulação das regras econômicas e políticas pelas grandes corporações transnacionais. 
Por meio de poucas e grandiosas empresas, a organização capitalista da produção de bens e serviços no mundo encontra-se integrada e sem paralelo histórico. São corporações extremamente grandes para quebrar, caso a ineficiência competitiva vier a ocorrer, o que transfere para a conta pública o ônus de manter e sustentar, sempre que necessário, os grandes grupos econômicos financeiros e não financeiros.

No segmento das grandes aeronaves, por exemplo, registra-se que somente duas grandes corporações transnacionais controlam a totalidade da produção. Na telefonia, fármacos, entre outros setores econômicos, permanece destacada a supremacia da grande empresa.

Tabela 01 - Grau de controle da rede global das corporações transnacionais segundo setor econômico

\begin{tabular}{lcc} 
Setor econômico & $\begin{array}{c}\text { Número de } \\
\text { corporações }\end{array}$ & Grau de monopólio \\
Grandes aeronáves & 2 & $100 \%$ \\
\hline Automobilístico & 10 & $100 \%$ \\
\hline Cigarros & 4 & $75 \%$ \\
\hline Computadores pessoais & 4 & $55 \%$ \\
\hline Construçãode equipamentos & 4 & $44 \%$ \\
\hline Equipamentos agrícolas & 3 & $69 \%$ \\
\hline Fármacos & 10 & $69 \%$ \\
\hline Infraestrutura de telecomunicações & 5 & $83 \%$ \\
\hline Microprocessadores para computador & 2 & $100 \%$ \\
\hline Telefonia móvel & 3 & $65 \%$ \\
\hline Pneus de automóveis & 3 & $75 \%$ \\
\hline Pneus de aviação & 3 & $100 \%$ \\
\hline Sistema operacional de computador & 1 & $90 \%$ \\
\hline Vidros de automóveis & 3 & $75 \%$ \\
\hline Vidros de tela de LCD & 2 & $78 \%$ \\
\hline
\end{tabular}

Fonte: Nolan; Zhang, 2010. In: Pochmann, 2015.

O esvaziamento da crença neoliberal explicitada pela crise atual tornou profundamente desacreditado tanto a vitalidade dos mercados 
desregulados como a suficiência do sistema financeiro internacional intermediado pelo dólar e assentado em derivativos. Desde 2008 que se percebe a difusão das práticas ainda maiores de socialismo dos ricos operadas por enormes ajudas governamentais às corporações transnacionais (bancos e empresas não financeiras).

A maior interpenetração governamental nos altos negócios ultramonopolistas privados globais decorre da ausência de Estados supranacionais capaz de melhorar as condições gerais de produção dos mercados (regulação da competição intercapitalista e apoio ao financiamento das grandes empresas). A viabilização do capital ultramonopolista global depende crescentemente do fortalecimento do Estado para além da atuação no espaço nacional.

A extrema concentração do poder privado tem desequilibrado a capacidade dos Estados nacionais estabelecerem contrapartidas à competição do setor produtivo atinentes às questões ambientais contemporâneas. Exemplo disso pode ser constatado no fato de 63 corporações transnacionais apresentarem faturamento superior aos orçamentos públicos de quase duas dezenas de Estados Nacionais no mundo.

A maior corporação transnacional, segundo a Revista Fortune, detinha em 2013 a somatória de suas receitas que a colocava na $11^{\mathrm{a}}$ posição na hierarquia dos orçamentos públicos dos Estados nacionais no mundo. Em nações como Espanha, Austrália, Coréia do Sul e Holanda, por exemplo, os orçamentos públicos eram inferiores ao montante do faturamento das duas maiores corporações transnacionais do mundo.

Não causa estranheza, portanto, o como as corporações transnacionais operam enquanto grandes fornecedores privados do setor público no interior dos processos licitatórios, conduzindo, muitas vezes, as distorções entre os interesses econômicos e o compromisso com a sustentabilidade ambiental. Mas diante da maior instabilidade 
do capitalismo submetido a poucas e gigantescas corporações transnacionais, nota-se que essas empresas tornam-se muito grandes para poder quebrar a lógica própria do mercado sob o risco de colapsar o meio ambiente.

Todavia, o estreitamento da relação cada vez mais orgânica do Estado com o processo de acumulação privada do capital global reverte-se em riscos de aprofundamento da competição entre os Estados nacionais. A agenda da degradação ambiental mantem-se ativa, porém distante de soluções viáveis.

Ademais, compreende-se como no interior dos processos políticos emerge cada vez mais a presença dos interesses econômicos, sobretudo das grandes corporações transnacionais. Elas financiam organismos não governamentais, partidos e políticos, influindo direta e indiretamente nos resultados eleitorais em cada país.

Como financiam parcialmente os meios de comunicação, por meio dos gigantescos gastos com publicidade e marketing, contaminam a “opinião pública”. Ao sofrer influência crescente do poder privado, o Estado nacional redireciona parte significativa de suas políticas públicas ao seu favor.

Não por outro motivo que o comprometimento dos orçamentos públicos com grandes corporações transnacionais esvazia políticas de apoio ao desenvolvimento sustentável. Da mesma forma, a internalização da revolução técnico-científica no processo de produção e consumo tende a ser mais postergada.

Pelo conhecimento produzido até o momento acerca da insustentável degradação ambiental gerada pelas atuais práticas de produção e consumo, sabe-se que a saída da crise global não poderia ser por meio da reprodução do passado. Mas para ser reestruturado, o padrão 
de produção e consumo precisaria rever consideravelmente a atual matriz energética mundial, o que implicaria penalizações e incentivos governamentais.

Ao mesmo tempo, a própria reformulação do sistema tributário, capaz de consagrar tributos tanto mais intensos às atividades de produção e consumo degradantes ambientalmente como mais suaves aos setores sustentáveis ao meio ambiente. O modelo mitigador dos efeitos negativos que decorrem das mudanças climáticas pressupõe o aparecimento de um conjunto de inovações técnico-científicas para fazer emergir o novo.

Da mesma forma, o avanço da sociedade dos serviços, cada vez mais apoiada no trabalho imaterial, tende a viabilizar uma profunda reorganização dos espaços urbanos, frutos das exigências do exercício do trabalho em locais apropriados (fazenda para a agricultura e pecuária, fábrica e indústria para a manufatura, entre outros). Pelo trabalho imaterial, a atividade laboral pode ser exercida em qualquer local, não mais em espaços previamente determinados e apropriados para isso (fábricas, canteiro de obras, fazendas), bem como em qualquer horário.

A qualificação da mão de obra em bases nacionais pode ser acompanhada simultaneamente pela atração de ocupações de maior qualidade e remuneração nos países com maior desenvolvimento da economia do conhecimento. Mas sem a reorganização social em comunidades territoriais fortalecidas na economia do conhecimento, o excedente de força de trabalho cresce, com atividades cada vez mais precárias e empobrecedoras em meio à acumulação de nova riqueza global. O resultado aponta para maior pressão no deslocamento geográfico do trabalho humano, em geral de regiões sustentadas por economias rurais e industriais para áreas concentradas nos setores de serviços. 


\section{Considerações gerais}

Após três décadas de vigência do Consenso de Washington, o mundo segue com limites significativos para a sustentação do crescimento das atividades econômicas e elevação do padrão de bem estar social. A dominância financeira tem impactado fortemente as decisões de produção e distribuição de bens e serviços, tornando as possibilidades de constituição de um novo padrão civilizatório ambientalmente sustentável mais distante.

O predomínio do sistema financeiro na economia real gerou ambiente vulnerável, permeado de crises e inseguranças em relação ao futuro. Simultaneamente, avança uma estrutura assimétrica de distribuição da riqueza e poder cada vez mais desigual.

Nas atuais condições da estrutura de poder, a expansão econômica tende a atender aos segmentos sociais já privilegiados e que se beneficiam da lógica do curto prazo gestado pela dominância financeira. Mesmo como os avanços tecnológicos, as possibilidades de haver sustentabilidade ambiental subvertem-se diante dos interesses mais imediatos por parte das grandes corporações transnacionais.

A constatação disso resulta da prevalência do padrão de produção e consumo cada vez mais globalizado e reflexo da desfiguração do que seja o essencial na constituição da vida decente e saudável. Em parte importante dos países, os orçamentos públicos refletem vultosas somas com despesas militares, subsídios e desonerações com grandes empresas, juros da dívida e bens e serviços distantes daqueles que poderiam permitir o enfrentamento da degradação ambiental e a elevação do bem estar social.

A sinalização inadequada por parte das políticas públicas à estrutura produtiva, com sistemas de incentivos e penalizações que não 
consideram a questão ecológica, decorre, em grande medida, do poder privado das grandes corporações transnacionais sobre os Estados nacionais. O desequilíbrio de poder no mundo faz da governança econômica e financeira global órgão auxiliar dos interesses de grupos econômicos cada vez menores, cujo horizonte da tendência à estagnação secular se explicita.

Como não se trata de oferta criar a sua própria demanda, assiste-se, então, à dominância financeira potencializar o risco colossal de uma crise prolongada, sem solução viável. O excesso de oferta de ativos financeiros não resulta em crédito aos quem deles precisam, o que gera especulação e bolhas a constranger cada vez mais a expansão da economia real.

Sem a industrialização, a democracia não funciona adequadamente. Mas para haver industrialização é necessário existir um Estado forte, o que contraria o Consenso de Washington e joga contra a construção de uma sociedade superior.

As promessas de um novo padrão civilizatório mais avançado pela passagem da sociedade urbano e industrial para a pós-industrial segue, após quatro décadas de serem anunciadas, postergadas. A modernidade capitalista neste início do século XXI conecta-se contraditoriamente com o passado do século XIX para algumas situações, como nos casos do avanço da pobreza, da desigualdade na repartição da renda e riqueza e da poder concentrado.

Atualmente, as diferenças entre nações e indivíduos seguem abissais. Pela convivência continuada com a tendência à estagnação da renda, os sinais contraditórios da regressão social se mantêm, com o empobrecimento de parcela da população mundial e ascensão dos ricos motivada pela nova condição de financeirização da riqueza. 